\title{
Prokrastinasi Akademik Ditinjau Dari Conscientiousness Pada Mahasiswa Fakultas Teknologi Dan Ilmu Komputer Universitas Prima Indonesia
}

\author{
Jason Kosasi \\ Fakultas Psikologi Universitas Prima Indonesia \\ jasonkosasi08@gmail.com \\ Nurmaizar Nilawati Siregar \\ Fakultas Psikologi Universitas Prima Indonesia \\ Nilawati_siregar@unprimdn.ac.id \\ Rianda Elvinawanty \\ Fakultas Psikologi Universitas Prima Indonesia \\ rianda@unprimdn.ac.id
}

\begin{abstract}
Abstrak
Prokrastinasi akademik merupakan kegiatan menunda tugas-tugas akademik yang menyebabkan kegagalan dalam menyelesaikan tugas dan dapat menurunkan performa akademik dari mahasiswa. Penelitian ini bertujuan untuk mengetahui hubungan antara conscientiousness dengan prokrastinasi akademik pada mahasiswa Fakultas Teknologi dan Ilmu Komputer sebanyak 97 mahasiswa. Hipotesis yang diajukan dalam penelitian ini adalah adanya hubungan negatif antara conscientiousness dengan prokrastinasi akademik. Pengujian hipotesis dilakukan dengan teknik Pearson Product Moment setelah dilakukan uji asumsi yang terdiri dari uji normalitas dan uji linearitas hubungan. Hasil analisis data menunjukkan koefisien Pearson sebesar -0,541 dengan $p<0.001$ dan menunjukkan ada hubungan negatif antara conscientiousness dengan prokrastinasi akademik. Hasil penelitian ini menunjukkan sumbangan yang diberikan conscientiousness terhadap prokrastinasi akademik adalah sebesar 29.3 persen, selebihnya 70.7 persen dipengaruhi oleh faktor lain yang tidak diteliti. Dari hasil penelitian ini dapat ditarik kesimpulan bahwa hipotesis penelitian dapat diterima.
\end{abstract}

Kata Kunci: conscientiousness, mahasiswa, prokrastinasi akademik

\section{Pendahuluan}

Zaman globalisasi yang terus maju dan berkembang ini, yang ditandai semakin tinggi tingkat persaingan yang sangat kompetitif di setiap kalangan. Perguruan tinggi adalah salah satu contoh dari pelaku persaingan tersebut, yang mana setiap individu harus bersaing agar mampu mendapatkan nilai yang 
memadai untuk dapat diperuntukkan di dunia kerja ke depannya. Kemampuan untuk bersaing dengan yang lainnya diperlukan oleh setiap individu, maka diperlukan sikap bersungguh-sungguh dalam proses belajar dan menyelesaikan tugas-tugas kuliah yang ada.

Mahasiswa yang menuntut ilmu di perguruan tinggi tidak akan pernah terlepas dari aktivitas belajar dan keharusan mengerjakan tugas-tugas studi. Salah satu kriteria mahasiswa yang berhasil adalah mahasiswa yang memiliki kemampuan mengatur waktu yang tepat dan memiliki batas waktu untuk setiap pengerjaan tugas-tugas akademik yang diterima oleh mahasiswa (Martin \& Osborne, dalam Yulista, 2008). Akan tetapi masih banyak mahasiswa yang sering melakukan penundaan terhadap tugas akademik mereka atau yang lebih dikenal dengan prokrastinasi akademik.

Prokrastinasi dapat diartikan sebagai menunda sampai hari esok, atau dari hari ke hari, umumnya berarti menangguhkan sesuatu yang berat dan tidak menyenangkan dan mengerjakannya dengan cara yang lebih buruk (Webster, dalam Andreou \& White, 2010). Istilah prokrastinasi digunakan untuk menggambarkan sesuatu kecenderungan menunda-nunda penyelesaian suatu tugas atau pekerjaan sehingga seseorang gagal menyelesaikan tugas-tugas tersebut tepat pada waktunya (Wie, dalam Zakia, dkk., 2010).

Andreou dan White (2010) menyatakan di lingkungan akademik, 80-85 persen mahasiswa perguruan tinggi di Amerika telah melakukan prokrastinasi. Temuan lain dari Burka dan Yuen (2008) menunjukkan pada tahun 2007, diperkirakan 75 persen mahasiswa di perguruan tinggi telah melakukan prokrastinasi, yang mana 50 persen mahasiswa telah melakukan prokrastinasi secara konsisten dan itu dianggap sebagai sebuah masalah dimana perilaku menunda mereka menyebabkan menurunnya performa akademik dan menciptakan perasaan tidak tenang dikarenakan hasil dari perilaku prokrastinasi mereka. Bentuk dari menurunnya performa akademik pada mahasiswa dapat dilihat dari keterlambatan pengumpulan tugas yang dibarengi dengan tidak maksimal dalam pengerjaan tugas tersebut, keterlambatan menghadiri perkuliahan, keterlambatan 
mengisi KRS, pengumpulan laporan PKL yang tidak tepat waktu, dan penyelesaian masa studi yang tidak tepat waktu.

Burka dan Yuen (2008) mengungkapkan dampak mengenai prokrastinasi yang mengganggu dalam dua hal, yaitu prokrastinasi menciptakan masalah eksternal, seperti menunda mengerjakan tugas membuat kita tidak dapat mengerjakan tugas dengan baik dan mendapatkan teguran dari dosen, prokrastinasi menimbulkan masalah internal, seperti merasa bersalah dan menyesal. Knaus (2010) mengatakan bahwa prokrastinasi yang dilakukan secara terus-menerus menyebabkan permasalahan yang serius bagi jutaan manusia, terutama yang berhubungan dengan nilai diri terhadap kinerja mereka dan prokrastinasi mungkin juga berkontribusi terhadap stres yang berkaitan dengan permasalahan kesehatan.

Pada kenyataannya, fenomena saat ini banyak mahasiswa yang melakukan perilaku penundaan. Pengamatan dan wawancara yang dilakukan oleh peneliti menemukan fenomena perilaku prokrastinasi atau menunda-nunda yang terjadi pada mahasiswa di Fakultas Teknologi dan Ilmu Komputer (FTIK) Universitas Prima Indonesia, seperti masih adanya mahasiswa yang terlambat menyelesaikan studinya tepat waktu, terlambat mengikuti perkuliahan, mahasiswa yang terlambat mengumpulkan tugas, tidak menghadiri perkuliahan lalu pergi nongkrong dengan teman-temannya, terlambat membayar uang kuliah dan terlambat dalam pengisian KRS dengan batas waktu yang telah ditentukan. Hasil observasi peneliti diperkuat dengan hasil wawancara dengan Kaprodi Teknik Informatika (TI) Universitas Prima Indonesia yang menuturkan bahwa mahasiwa TI sering melakukan penundaan-penundaan dalam bidang akademik, seperti keterlambatan pengumpulan tugas, terlambat menghadari perkuliahan, terlambat menyelesaikan PKL mereka, dan terlambat menyelesaikan studinya tepat waktu.

Banyak faktor yang dapat mempengaruhi prokrastinasi akademik, salah satunya adalah conscientiousness. Conscientiousness adalah kontrol sifat impulsif yang diperoleh dari lingkungan sosial terhadap perilaku yang berorientasi pada tujuan dan tugas (Lay, dalam Scher \& Osterman, 2002). Individu dengan karakter 
kepribadian ini akan mampu mengendalikan dorongan diri dan memfokuskan diri pada tujuan yang akan dicapai.

Conscientiousness mendeskripsikan individu yang memiliki kontrol terhadap lingkungan sosial, berpikir sebelum bertindak, menunda kepuasan, mengikuti peraturan dan norma, terencana, dan memprioritaskan tugas (Ewen, 2003). Individu yang memiliki tingkat conscientiousness yang rendah menunjukkan sikap yang malas, tidak terarah, dan mudah teralih perhatiannya. Orang yang conscientiousness rendah biasanya ceroboh, berantakan, tidak terarah, mudah teralih perhatiannya, dan tidak dapat diandalkan (Friedman, dalam John, dkk., 2008).

Menurut Ryckman (2008) seorang anak yang rendah pada nilai faktor conscientiousness akan mengalami gangguan pada kemampuan mereka dalam membaca, dan pada anak remaja yang rendah dalam nilai faktor conscientiousness memiliki masalah dalam menyesuaikan diri dan berkinerja buruk di sekolah. Seseorang yang rendah dalam conscientiousness menyebabkan masalah yang luas pada sekolah dan hubungan dengan orang lain (John, dkk., 2008).

Suatu penelitian yang dilakukan oleh Schouwenberg dan Lay (1995) mengungkapkan bahwa terdapat arah hubungan yang negatif antara conscientiousness dan prokrastinasi akademik. Artinya semakin tinggi conscientiousness maka akan semakin rendah prokrastinasi akademik pada mahasiswa. Sebaliknya, semakin rendah conscientiousness maka akan semakin tinggi tingkat prokrastinasi akademik pada mahasiswa. Di tahun yang lain, Lay, dkk., (1998) kembali menguji hubungan antara conscientiousness dengan prokrastinasi akademik yang hasilnya juga menunjukkan bahwa conscientiousness berkorelasi negatif terhadap prokrastinasi akademik. Seseorang yang kurang akan sifat kesadaran akan cenderung malas, tidak teratur, tidak memiliki fokus, dan bersikap sembrono. Dengan kata lain, Semakin tinggi tingkat sifat kesadaran seseorang akan menurunkan kecenderungan perilaku menunda-nunda seseorang. Berdasarkan penelitian tersebut dapat dilihat bahwa perilaku menunda-nunda akan tereduksi dan hilang apabila seorang mahasiswa memiliki kesadaran yang kuat akan tujuan yang akan dicapai di kemudian hari. 
Dalam penelitian ini, peneliti ingin membuktikan bahwa conscientiousness dari seseorang dapat berkontribusi pada prokrastinasi akademiknya. Dengan mengetahui kontribusi conscientiousness terhadap prokrastinasi akademik mahasiswa, maka diharapkan dapat menjadi sumber referensi untuk mengurangi perilaku penundaan akademik yang dapat menghambat penyelesaian studi mahasiswa itu sendiri.

Hal yang membedakan penelitian ini dengan penelitian-penelitian terdahulu adalah skala prokrastinasi akademik yang peneliti kembangan sendiri sesuai dengan indikator-indikator prokrastinasi akademik menurut Tuckman (1990) dan skala conscientiousness yang peneliti kembangkan sendiri berdasarkan aspek-aspek conscientiousness menurut McCrae dan Costa (dalam Costa \& Widiger, 2002) dengan susunan aitem yang lebih mudah dipahami oleh mahasiswa. Adapun alasan dipilihnya mahasiswa semester VI Program Studi Teknik Informatika Fakultas Teknologi dan Ilmu Komputer Universitas Prima Indonesia adalah karena pada semester ini, para mahasiswa memiliki lebih banyak tugas dan beban SKS yang lebih banyak dari semester-semester sebelumnya. Selain itu, para mahasiswa juga sudah harus menyiapkan diri dengan skripsi dan PKL.

\section{Metode}

Jenis penelitian ini adalah penelitian kuantitatif dengan pendekatan korelasional. Penelitian korelasional merupakan teknik pengelolaan data dengan cara mengorelasikan dua data variabel atau lebih untuk mengetahui tingkat keeratan hubungan (Siswanto, dkk., 2017). Teknik analisis data dalam pengujian hipotesis pada penelitian ini menggunakan Pearson Product Moment untuk melihat hubungan variabel bebas dengan variabel terikat.

Populasi dalam penelitian ini sebanyak 130 mahasiswa semester VI Program Studi Teknik Informatika Universitas Prima Indonesia Medan. Adapun alasan dalam pemilihan mahasiswa semester VI dikarenakan pada semester tersebut jumlah mata kuliah (SKS) mencapai titik maksimal sehingga lebih mudah dalam melihat perilaku-perilaku penundaan akademik. Penelitian ini melibatkan 
97 mahasiswa semester VI Program Studi Teknik Informatika Universitas Prima Indonesia Medan yang dipilih dengan teknik purposive sampling dengan kriteria subjek merupakan mahasiswa kelas regular, sedang dalam semester VI, dan mahasiswa program studi Teknik Informatika.

Data dikumpulkan dengan menggunakan skala pengukuran untuk mengukur perilaku prokrastinasi akademik dan kepribadian conscientiousness. Skala prokrastiansi akademik dibuat berdasarkan indikator-indikator prokrastinasi akademik yang dikemukakan sebelumnya menurut Tuckman (1990) yang terdiri dari: cenderung menunda dan meninggalkan pekerjaan, cenderung sulit melakukan pekerjaan yang tidak menyenangkan dan jika memungkinkan mengelak atau menolak keadaan tidak menyenangkan, dan cenderung menyalahkan orang lain atas keadaan sulit yang dihadapi karena penundaan. Total aitem untuk skala prokrastinasi akademik sebanyak 48 aitem yang terdiri dari 16 aitem untuk masing-masing indikator yang terdiri dari 8 aitem favourable dan 8 aitem unfavourable. Skala conscientiousness peneliti kembangkan berdasarkan aspek-aspek conscientiousness yang dikemukakan sebelumnya menurut McCrae \& Costa (Costa \& Widiger, 2002), yaitu: competence, order, dutifulness, achievement-striving, self-discipline dan deliberation. Total aitem untuk skala conscientiousness sebanyak 48 aitem yang terdiri dari 8 aitem untuk masingmasing aspek yang terdiri dari 4 aitem favourable dan 4 aitem unfavourable.

Sebelum pengambilan data penelitian, peneliti melakukan try out terlebih dahulu terhadap 83 mahasiswa Fakultas Kesehatan Masyarakat Universitas Prima Indonesia Medan yang sesuai dengan karakteristik yang ditetapkan pada subjek penelitian. Setelah dilakukan try out, ditemukan hasil uji coba skala yang dijelaskan di bawah ini.

Pengujian validitas dilakukan dengan menggunakan rumus corrected item total correlation. Aitem dinyatakan valid apabila nilai daya diskriminasi aitemnya $\geq 0.3$ (Azwar, 2016). Hasil uji validitas terhadap Skala Prokrastinasi Akademik ditemukan nilai $\mathrm{r}_{\mathrm{ix}}$ bergerak dari 0.302 hingga 0.534 sehingga sebanyak 9 aitem dinyatakan gugur. Total aitem yang digunakan dalam penelitian ini sebanyak 39 aitem untuk mengukur perilaku prokrastinasi akademik subjek penelitian. 
Reliabilitas Skala Prokrastinasi Akademik ini diuji dengan teknik Alpha Cronbach yang menunjukkan hasil $\alpha=0.899$. Sehingga dapat disimpulkan Skala Prokrastinasi Akademik ini sudah reliabel karena sudah memenuhi koefisien reliabilitas yang baik, yaitu di atas 0.6 (Sugiyono, dalam Siswanto, dkk., 2017).

Dalam menguji data yang diperoleh dari Skala Conscientiousness juga digunakan rumus corrected item total correlation. Aitem dinyatakan valid apabila nilai daya diskriminasi aitemnya $\geq 0.3$ (Azwar, 2016). Hasil uji validitas terhadap Skala Conscientiousness ditemukan nilai $\mathrm{r}_{\mathrm{ix}}$ bergerak dari 0.306 hingga 0.603 sehingga sebanyak 11 aitem dinyatakan gugur. Total aitem yang digunakan dalam penelitian ini sebanyak 37 aitem untuk mengukur kepribadian conscientiousness subjek penelitian. Reliabilitas Skala Conscientiousness ini diuji dengan teknik Alpha Cronbach yang menunjukkan hasil $\alpha=0.888$. Sehingga dapat disimpulkan Skala Conscientiousness ini sudah reliabel karena sudah memenuhi koefisien reliabilitas yang baik, yaitu diatas 0.6 (Sugiyono, dalam Siswanto, dkk., 2017).

Setelah mendapatkan hasil uji validitas dan reliabilitas yang baik, peneliti kemudian menyebarkan kuesioner kepada 97 mahasiswa yang menjadi subjek dalam penelitian ini. Setelah data terkumpul, peneliti melakukan pengolahan data dan uji hipotesis dengan Pearson Product Moment.

\section{Hasil dan Pembahasan}

Tabel 1. Data Deskriptif Conscientiousness dan Prokrastinasi Akademik

\begin{tabular}{cll}
\hline & Conscientiousness & Prokrastinasi Akademik \\
\hline Skor Minimum & 51 & 88 \\
\hline Skor Maximum & 111 & 154 \\
\hline Mean Empirik & 84.32 & 115.03 \\
\hline Mean Hipotetik & 92.5 & 97.5 \\
\hline Standar Deviasi & 13.10 & 11.64 \\
\hline Kategori Rendah (Persentase) & $15(15.47 \%)$ & $0(0 \%)$ \\
\hline Kategori Sedang (Persentase) & $81(83.50)$ & $51(57.70 \%)$ \\
\hline Kategori Tinggi (Persentase) & $1(1.03 \%)$ & $46(42.30 \%)$ \\
\hline
\end{tabular}

Berdasarkan pada tabel 1, pada variabel conscientiousness terdapat 15 (15.47 persen) subjek yang memiliki conscientiousness yang rendah, terdapat 81 
(83.50 persen) subjek yang memiliki conscientiousness yang sedang, dan terdapat 1 (1.03 persen) subjek yang memiliki conscientiousness yang tinggi. Berdasarkan hasil tersebut maka dapat disimpulkan bahwa rata-rata subjek penelitian memiliki conscientiousness pada kategori sedang.

Dari Skala Conscientiousness yang diisi subjek, diperoleh mean empirik sebesar 84.32 dengan standar deviasi 13.10. Apabila mean empirik > mean hipotetik maka hasil penelitian yang diperoleh akan dinyatakan tinggi dan sebaliknya jika mean empirik < mean hipotetik maka hasil penelitian akan dinyatakan rendah. Hasil analisis untuk Skala Conscientiousness diperoleh mean empirik < mean hipotetik yaitu 84.32 < 92.5 maka dapat disimpulkan bahwa conscientiousness pada subjek penelitian lebih rendah daripada populasi pada umumnya.

Selanjutnya, untuk hasil kategorisasi variabel prokrastinasi akademik menunjukkan bahwa tidak ditemukan subjek (0 persen) yang memiliki prokrastinasi akademik yang rendah, terdapat 51 (57.70\%) subjek yang memiliki prokrastinasi akademik yang sedang, dan terdapat 46 (42.30\%) subjek yang memiliki prokrastinasi akademik yang tinggi. Berdasarkan hasil tersebut maka dapat disimpulkan bahwa rata-rata subjek penelitian memiliki prokrastinasi akademik pada kategori yang sedang.

Dari Skala Prokrastinasi Akademik yang diisi subjek, diperoleh mean empirik sebesar 115.03 dengan standar deviasi 11.64. Apabila mean empirik > mean hipotetik maka hasil penelitian yang diperoleh akan dinyatakan tinggi dan sebaliknya jika mean empirik < mean hipotetik maka hasil penelitian akan dinyatakan rendah. Hasil analisis untuk skala prokrastinasi akademik diperoleh mean empirik > mean hipotetik yaitu 115.03 > 97.5 maka dapat disimpulkan bahwa prokrastinasi akademik pada subjek penelitian lebih tinggi daripada populasi pada umumnya.

Uji normalitas pada variabel conscientiousness diperoleh koefisien KS-Z = 0.911 dengan Sig sebesar 0.189 untuk uji 1 (satu) ekor ( $p>0.05$ ), yang dapat diartikan bahwa data pada variabel conscientiousness memiliki sebaran yang normal. Uji normalitas yang dilakukan terhadap variabel prokrastinasi akademik 
diperoleh koefisien KS-Z = 0.811 dengan Sig sebesar 0.263 untuk uji 1 (satu) ekor ( $\mathrm{p}>0.05$ ), yang dapat diartikan bahwa data pada variabel prokrastinasi akademik memiliki sebaran yang normal. Hasil Uji Normalitas dapat dilihat pada tabel 2 di bawah ini:

Tabel 2. Hasil Uji Normalitas

\begin{tabular}{cccccc}
\hline Variabel & SD & K-SZ & Sig. & P & Keterangan \\
\hline $\begin{array}{c}\text { Conscientiousness } \\
\text { Prokrastinasi }\end{array}$ & 13.103 & 0.911 & 0.189 & $\mathrm{p}>0.05$ & Sebaran normal \\
Akademik & 11.644 & 0.811 & 0.263 & $\mathrm{p}>0.05$ & Sebaran normal \\
\hline
\end{tabular}

Variabel conscientiousness dan prokrastinasi akademik memiliki hubungan linear. Hal ini terlihat dari nilai $\mathrm{P}$ yang diperoleh yaitu $0.000(\mathrm{p}<0.05)$, maka dapat disimpulkan kedua variabel memiliki hubungan yang linear dan telah memenuhi syarat untuk dilakukan analisis korelasi Pearson Product Moment. Hasil Uji Linearitas dapat dilihat pada tabel 3 sebagai berikut:

Tabel 3. Hasil Uji Linearitas

\begin{tabular}{cccc}
\hline Variabel & F & P & Keterangan \\
\hline $\begin{array}{c}\text { Conscientiousness } \\
\text { Prokrastinasi Akademik }\end{array}$ & 40.313 & 0.000 & Linear \\
\hline
\end{tabular}

Setelah uji asumsi diterima, selanjutnya dilakukan uji hipotesis. Hipotesis dalam penelitian ini adalah hubungan negatif antara prokrastinasi akademik dengan conscientiousness. Hasil yang diperoleh menunjukkan bahwa ada hubungan signifikan negatif antara conscientiousness dengan prokrastinasi akademik dengan koefisien korelasi product moment sebesar $\mathrm{r}=-0.541$ yang berada pada rentang 0.4-0.599 sehingga dikategorikan memiliki hubungan yang sedang dan nilai $\mathrm{p}$ sebesar $0.000(\mathrm{p}<0.001)$ yang artinya semakin tinggi tingkat conscientiousness yang dimiliki maka semakin rendah prokrastinasi akademik. Sebaliknya semakin rendah conscientiousness yang dimiliki maka semakin tinggi prokrastinasi akademik. Hasil Uji Hipotesis dapat dilihat pada tabel 4 di bawah ini: 
Tabel 4. Hasil Uji Hipotesis

\begin{tabular}{lcccc}
\hline Analisis & $\begin{array}{c}\text { Pearson Product } \\
\text { Moment }\end{array}$ & $\boldsymbol{R}$ & $\boldsymbol{R}$ Square & Std. Error of the Estimate \\
\hline Koefisien & -0.541 & -0.541 & 0.293 & 9.843 \\
Sig. & 0.000 & & & \\
\hline
\end{tabular}

Dalam penelitian ini ditemukan nilai koefisien determinasi $\left(\mathrm{R}^{2}\right)$ sebesar 0.293. Berdasarkan hasil tersebut, dapat disimpulkan bahwa sumbangan 29.3 persen conscientiousness mempengaruhi prokrastinasi akademik dan selebihnya 70.7 persen dipengaruhi oleh faktor lain, seperti konformitas, kontrol diri, penyesuaian diri, regulasi diri, self-compassion, efikasi diri, harga diri, dan dukungan sosial. Costa, dkk., (dalam Ferrari, dkk., 1995) menyimpulkan bahwa individu yang rendah dalam beberapa aspek dari conscientiousness rentan terhadap prokrastinasi dan mudah menyerah ketika dihadapkan dengan keadaan yang berat.

Hasil yang senada juga ditemukan pada penelitian yang dilakukan oleh Surijah dan Tjundjing (2007) di sebuah Fakultas Psikologi di Surabaya. Mereka menemukan bahwa conscientiousness dalam diri seseorang memiliki hubungan dengan prokrastinasi akademik, yang mana seseorang dengan conscientiousness tinggi akan memiliki sikap terencana, terstruktur, tekun, serta memiliki kendali diri yang baik. Dengan demikian, seseorang yang memiliki conscientiousness tinggi akan lebih jarang melakukan penundaan-penundaan pada tugas-tugas akademik mereka.

Hasil penelitian ini juga sejalan dengan penelitian yang telah dilakukan sebelumnya oleh Watson (2001) di sebuah universitas yang berjumlah 349 mahasiswa. Hasil penelitian ini berbunyi bahwa dengan memiliki conscientiousness yang rendah menyebabkan seseorang melakukan penundaan dalam melakukan tugas-tugas administratif dan keterlambatan menghadiri suatu pertemuan. Apabila seseorang memiliki conscientiousness yang tinggi mereka cenderung tidak memiliki sifat-sifat tersebut sehingga dapat mengurangi perilaku penundaan. 
Dari hasil penelitian ini, diketahui prokrastinasi akademik pada mahasiswa Program Studi Teknik Informatika Fakultas Teknologi dan Ilmu Komputer adalah tinggi. Selain itu, banyak mahasiswa yang harus mengulang beberapa mata kuliah di semester yang akan datang dikarenakan nilai ujian yang tidak mencukupi, tidak mengerjakan tugas-tugas perkuliahan, dan tidak menghadiri perkuliahan melebihi $40 \%$ total kehadiran. Padahal hal tersebut dapat dihindari dengan menghindari melakukan penundaan-penundaan pada kegiatan-kegitatan akademik, sehingga mereka dapat dengan cepat menyelesaikan studinya.

Keterbatasan dalam penelitian ini terdapat pada faktor di luar seperti bekerja atau tidak bekerja mahasiswa dan peneliti hanya mengukur berdasarkan salah satu trait kepribadian yaitu kepribadian conscientiousness saja. Sehingga, tidak dapat diketahui hubungan trait-trait kepribadian lainnya seperti agreeableness, extraversion, openness to experience, dan neuroticism dengan prokrastinasi akademik.

\section{Kesimpulan dan Saran}

\section{Kesimpulan}

Berdasarkan penelitian yang telah dilakukan, ditemukan ada hubungan negatif antara conscientiousness dengan prokrastinasi akademik dengan nilai koefisien korelasi product moment $=-0.541$ dan $\mathrm{p}=0.000(\mathrm{p}<0.001)$, dan nilai $R$ square $\left(\mathrm{R}^{2}\right)=0.293$. Conscientiousness yang tidak terpenuhi akan dapat membuat mahasiswa sering melakukan prokrastinasi atau menunda-nunda mengerjakan tugas mereka yang pada akhirnya dapat mempengaruhi performa akademik mereka. Hasil penelitian ini menunjukkan bahwa sumbangan yang diberikan variabel conscientiousness terhadap variabel prokrastinasi akademik adalah sebesar 29.3 persen, selebihnya 70.7 persen dipengaruhi oleh faktor lain yang tidak diteliti, seperti konformitas, kontrol diri, penyesuaian diri, regulasi diri, selfcompassion, efikasi diri, harga diridan dukungan sosial. 


\section{Saran}

1. Saran bagi mahasiswa

Berdasarkan penelitian yang telah dilakukan, maka disarankan mahasiswa agar dapat lebih memperhatikan secara sungguh-sungguh studi meraka agar dapat menghindari perilaku menunda-nunda dan dapat menyelesaikan studi tepat waktu. Mahasiswa dapat membuat jadwal-jadwal mengenai tugas-tugas yang akan dilakukan, sehingga akan mempermudah mahasiswa dalam mengetahui prioritas tugas mana yang lebih memerlukan pengerjaan terlebih dahulu.

2. Saran kepada Fakultas

Diharapkan hasil dari penelitian ini dapat dijadikan sebagai sebuah gambaran mengenai mahasiswa pada Program Studi Teknik Informatika Fakultas Teknologi dan Ilmu Komputer yang tingkat prokrastinasi akademik berada di tingkat sedang. Disarankan kepada pihak Prodi untuk melakukan komunikasi secara personal kepada mahasiswa yang gagal dalam banyak matakuliah untuk mengetahui apa permasalahan mereka dan dapat memberikan arahan dalam mengatasi apa yang menjadi permasalahan mereka.

3. Saran kepada peneliti selanjutnya

Bagi peneliti selanjutnya diharapkan dapat mencari faktor lain seperti konformitas, kontrol diri, penyesuaian diri, regulasi diri, self-compassion, efikasi diri, harga diridan dukungan sosial yang dapat berpengaruh terhadap prokrastinasi akademik.

\section{DAFTAR PUSTAKA}

Andreou, C., \& White, M, D. (2010). The Thief of Time Philosophical Essays On Procrastination. New York: Oxford University Press.

Azwar, S. (2016). Sikap Manusia Teori dan Pengukurannya Edisi Kedua. Yogyakarta: Pustaka Pelajar.

Burka, J. B., \& Yuen, L. M. (2008). Procrastination; Why you do it, what to do about it now. Cambridge: Da Capo Press. 
Costa, P. T. Jr., \& Widiger, T. A. (2002). Personality Disorders and The Big FiveFactor Model of Personality. Washington. DC: American Psychological Association.

Endrianto, C. (2014). Hubungan antara self control dan prokrastinasi akademik berdasarkan TMT. Calyptra: jurnal ilmiah mahasiswa Universitas Surabaya, 3(1), 1-11.

Ewen, R. B. (2003). An Introduction to Theories of Personality. New Jersey: Lawrence Erlbaum Associates.

Ferrari, J. R., Johnson, J. L., \& McGown, W. G. (1995). Procrastination and task avoidance; Theory, research, and treatment. New York: Plenum Press.

John, O. P., Robins, R. W., \& Pervin, L. A. (2008). Handbook of Personality: Theory and Research. New York: The Guilford Press.

Knaus, W. (2010). End Procrastination Now! Get It Done With A Proven Psychological Approach. New York: The McGraw -Hill.

Lay, Kovacs, A., \& Danto, D. (1998). The relation of trait procrastination to the big-five factor conscientiousness: an assessment with primary-junior school children based on self-report scales. Personality and Individual Differences 25(2), 187-193.

Prayitno, D. (2011). Teknik Mudah dan Cepat Melakukan Analisis Data Penelitian dengan SPSS. Yogyakarta: Gaya Media.

Raad, B. D. (2000). The Big Five Personality Factors: The Psycholexical Approach to Personality. Germany: Hogrefe \& Huber Publishers.

Ryckman, R. M. (2008). Theories of Personality $9^{\text {th }}$ Ed. USA: Thomson Wadsworth.

Scher, S. J., \& Osterman, N. M. (2002). Procrastination, conscientiousness, anxiety, and goals: Exploring the measurement and correlates of procrastination among school-aged children. Psychology in The School, 39(4), 385-398.

Schouwenburg, H. C., \& Lay, C. H. (1995). Trait procrastination and the big five factors personality. Personality and Individual Differences, 18(4), 481-490.

Siswanto, Susila, \& Suyanto. (2017). Metodologi Penelitian Kombinasi Kualitatif Kuantitatif Kedokteran dan Kesehatan. Klaten: Bossscript. 
Surijah, A. E., \& Tjundjing, S. (2007). Mahasiswa versus tugas : Prokrastinasi akademik dan conscientiousness. Anima, Indonesian Psychology Journal, 22(4), 352-374.

Tuckman, B. W. (1990). Measuring procrastination attitudinally and behaviourally. Educational resources information center (ERIC)ED 319 792.

Watson, D. C. (2001). Procrastination an the five-factor model a facet level analysis. Personality and Individual Differences, 30(1), 149-158. 